\title{
THE CYCLE OF MONEY WITH AND WITHOUT THE ESCAPED SAVINGS
}

\author{
Constantinos Challoumis \\ National and Kapodistrian University of Athens, 1 Sofokleous Str., \\ Athina 105 59, Greece. \\ Coresponding: challoumis_constantinos@yahoo.com \\ Professional work \\ Recceived: 21.11.2018; accepted: 23.04.2019;
}

\begin{abstract}
The escaped savings are critical for the cycle of money, as express the amount of money which leak from an economy and not return back to make more economic cycles. This paper is about the comparison of the cycle of money including the escaping savings and without the escaping saving. Then, it is plausible to extract the appropriate conclusions about the utility of savings in an economy when there the savings return to the market for investments and for consumption and when these savings are omitted and lost from the market for a long term period. For the purposes of this analysis is used the Q.E. method and the R.B.Q. model.
\end{abstract}

\section{The cycle of money}

The cycle of money is a theory which based on the idea that the public and tax authorities should boost the small or medium enterprises with lower taxes and from the bigger companies to retain low taxes only for production units e.g. factories etc. The bigger companies which overlap smaller companies make weaker the economy as the money that they receive don't return back to the society. The sense of escape savings is about the money which leak from an economy and don't return back for consumption, investments and reinvestments. This paper is about the ideal case of the cycle of money and its normal form. This could happen when there are escaping savings and when there are no escaping savings. This economic comparison has as result that in a market the consumption and the investments are in the maximum level when there are no escaping savings. Therefore the appropriate tax rate is the key element for the appropriate public policy. The fixed length principle serves the public policy with the lower taxation of uncontrolled transactions and the higher taxation of the controlled transactions. 
Challoumis $C$., The cycle of money with and without the escaped savings

\section{Theoretical background and the applied methodology}

The contracts and the agreements between the participants of control transactions are these which determine the allocation of profits and losses. To the agreements should be mentioned the changes in the contracts. This is the reason why the tax authorities should make periodic inspections. The periodic specification of contracts is important for the comparability analysis. These periodic inspections of the companies which participate in controlled transactions are crucial for the arm's length principle. Then, the determination of the cost sharing depends from the periodic check of companies which are tested parties. ${ }^{1}$ The scope of the companies of controlled transactions is to face the issues that are connected with the taxation of their activities. Therefrom, the requirements for the companies of controlled transactions with the tax authorities should be in the range of the arm's length principle. Thereupon, the appropriate agreement of the companies of controlled transactions is that which permits them the maximization of their profits in tax environments with low tax rate, and the maximization of costs in economic environments with high tax rate.

Moreover should be notified that the companies of controlled transactions and the same time the inspections of tax authorities are done under the condition of the proportional adjustments. ${ }^{2}$ The interpretation of the condition of the proportional adjustments is that the companies which participate in controlled transactions many times don't have the appropriate data and uncontrolled transactions of similar circumstances to compare and therefore they adjust their data with proportional way.[1][2] This means that if the companies which are tested parties conclude that the profits and losses of companies from uncontrolled transactions are much higher or much fewer then they make proportional analogy to compare them with their data.

The production of goods or services creates profits and costs to the companies. ${ }^{3}$ Based on the prior scrutiny we have that:

$u=s(z f+\tilde{z} d)$

$z=|\tilde{z}-1|$

The symbol $u$ is about the impact factor of the comparability analysis which has any method to thes. 5 The symbol $\mathrm{z}$ is a coefficient which takes values between 0 and 1 . What value could receive is determined by the influence of the method (using the best method rule) to thes. The symbol of $f$ is about the cost which comes up from the production of goods, and the symbol of $d$ is about the cost which comes from the distribution of the goods.

According to equations from (1) to (6) is plausible to determine the following equations:

$u_{c}=z f+\tilde{z} d$ 
and

$\mathrm{b}=\left(\mathrm{p}-u_{c}\right) * j_{1}$

The symbol of $b$ in the prior equation is about the amount of taxes that should pay the companies of controlled transactions in the application of the arm's length principle. The $u_{c}$ is the amount of tax obligations that can avoid through the allocations of profits and losses. Moreover, $j_{1}$ is a coefficient for the rate of taxes. Then, the equation (8) shows the case of the arm's length principle. In addition the case of fixed length principle we have the next equation:

$v=\mathrm{p}^{*} j_{2}$

The symbol of $v$ in the previous equation shows the taxes that should pay the enterprises of controlled transactions in the application of the fixed length principle. Then, $j_{2}$ is a coefficient for the rate of taxes in the case of fixed length principle. Thereupon, we conclude according the prio theory that: (10)

$v \geq b$
The tax for the companies which participate in controlled transactions of transfer pricing in the case of fixed length principle is higher or at least equal with than of the case of the arm's length principle.

Thereupon, with the fixed length principle the enterprises of controlled transactions are able to tackle issues which come from the allocation of the profits and losses. Thence, the tax authorities are able to face the transfer pricing effects to the global tax revenue. [3][4][5][6]

The fixed length principle permits to recover the tax losses of the global tax revenue from the controlled transactions of the transfer pricing. In the next scheme is illustrated the procedure that companies of controlled transactions follow for their allocations of profits and losses, the proportional adjustments of data, and the fixed length principle. [7][8][9][10][11] Thence, we have that:

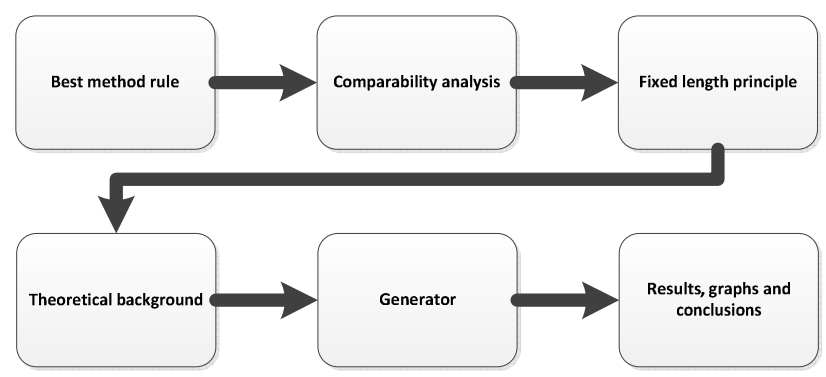

Figure 1: Cost sharing and application of fixed length principle 
In the figure 1 is determined the procedure of the fixed length principle and its quantity analysis for the determination of the behavior of the model. In the next section is presented the theory of cycle of money. Moreover, the methodology which followed stands on the Q.E. method.

\section{The normal case of cycle of money and the ideal case of cycle of money}

The tax revenues correspond to the savings that the companies could have if the taxes were avoided. The way that these savings are administrated is different from case to case. Then the benefits of the companies could be managed in a completely different way, as could be saved or could be taxed. The theory of cycle of money shows when the savings robust the economy and when the taxes robust the economy. It is crucial for this determination to be a separation of savings into the non-returned savings (or escaped savings) and into the returned savings (or enforcement savings). For the scope of this analysis below are demonstrated the equations which are:

$$
\begin{aligned}
& \alpha=\alpha_{s}+\alpha_{t}, \dot{\mathrm{n}}, \frac{1}{v}+\alpha_{t} \\
& x_{m}=m-a \\
& \mathrm{~m}=\mu+\alpha_{p} \\
& \mu=\sum_{\iota=0}^{n} \mu_{\iota} \\
& \alpha_{p}=\sum_{j=0}^{m} \alpha_{p j} \\
& c_{m}=\frac{d x_{m}}{d a}
\end{aligned}
$$

$$
c_{\alpha}=\frac{d x_{m}}{d m}
$$

$c_{y}=c_{m}-c_{\alpha}$

The variable of ais symbolized the case of the escaped savings. This means that we have savings which are not return back to the economy, or come back after long term period. The variable of $\alpha_{s}$ symbolizes the case that we have escaped savings which come from transfer pricing activities. The variable of $\alpha_{t}$ is symbolizes the case that we have escaped savings not from transfer pricing activities but from any other commercial activity. For instance $\alpha_{t}$ could refer to the commercial activities which come from the uncontrolled transactions. The variable of $m$ symbolizes the financial liquidity in an economy. The variable of $\mu$ symbolizes the consumption in an economy. The variable of $\alpha_{p}$ symbolizes the enforcement savings, which come from the citizens and from small and medium sized enterprises. The variable of $x_{m}$ symbolizes the condition of financial liquidity in an economy. The variable of $c_{m}$ symbolizes the velocity of financial liquidity increases or decreases. The variable of $c_{\alpha}$ symbolizes the velocity of escaped savings. Therefore, the variable of $c_{y}$ symbolizes the term of the cycle of money. Thereupon, the cycle of money shows the level of dynamic of an economy, and its robustness.

Then, we have the following basic principles about the cycle of money:

- The citizens, the small and the middle sized enterprises substi- 
tute the services and the property of the companies which save their money and not invest them or consume it proportionally in the economy. Thereupon, the companies of the controlled transactions are the main cause for the escape savings.

- The escaped savings are responsible for the decline of the economic dynamic of the economy. The key point of escape savings is that the companies of controlled transactions of transfer pricing are responsible for the not reenter of these amount of money in the market. This situation causes the lack of financial liquidity in an economy.

- The substitution of controlled transactions is not substituted from the citizens and from the small and middle size companies when there is not plausible to offer the same added value to the products and to the services. This case happens especially in the instance of factories, in the research centers etc. Therefrom, these cases in the appropriate tax policy should taxed as uncontrolled transactions independently if the they participate in controlled transactions (using the fixed length principle).

- The enforcement savings are responsible for the high economic dynamic of the economy. Therefore, the investments and the consumption are these elements which come from the savings of the citizens and the small and the middle size companies.
- The velocity of financial liquidity shows how rapidly the economy robustness grows or declines accordingly. Then is an index for how well structured is any economy.

- The velocity of escaped savings shows how rapidly the non-return savings are lost from the market, or by the lack of investments, or by the lack of consumption.

- The cycle of money represents the condition of the economy. The level of well-structured tax system, and in general the dynamic of the economy. It this indicator is high then the economy could has high robustness otherwise has low financial liquidity.

- As controlled transactions in the theory of cycle of money is considered not only the cases of transfer pricing, but any kind of administration of profits and losses to avoid taxation.

- As uncontrolled transactions in the theory of cycle of money is the case of commercial activity of citizens, the small and medium size enterprises, the factories, the research centers, and any kind of commercial activity that cannot substitute by the companies of controlled transactions.

- The fixed length principle tackles issues subjects like the case cycle of money. But, this doesn't mean that restrictive must apply the fixed length principle as the cycle of money is more widely theory 
Challoumis $C$., The cycle of money with and without the escaped savings

which exceeds the transfer pricing scope.

Therefrom, we obtain that the cycle of money is grow when there is a tax system like the case of fixed length principle which permits the low taxation of the uncontrolled transactions and the higher taxation of controlled transactions. Should be mentioned that as uncontrolled transactions are considered and the cases of the financial liquidity of citizens and of the small and middle size companies. The prior analysis is illustrated in the next scheme:

(a)

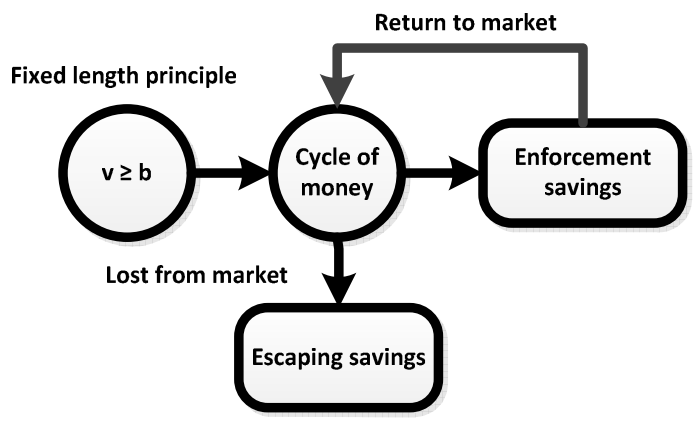

(b)

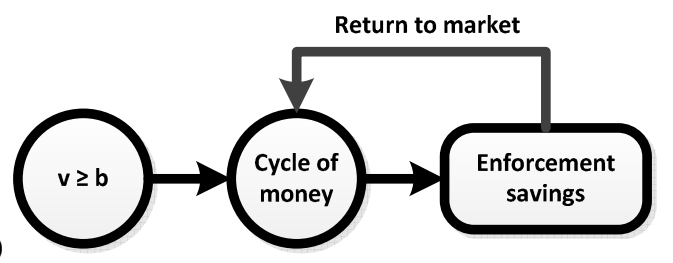

Figure 2: (a) Cycle of money (b) Ideal case of cycle of money

In the figure 2 (a) showed the case of the escaping savings and the enforcement savings. Then, we have the connection of the higher tax policy for the controlled transactions and the lower tax policy for the uncontrolled transactions which is supported by the fixed length principle. In the model of the cycle of money without the escaping savings [figure 2(b)] we have the ideal case where no lost savings happen in the market. Therefore, in the second scheme we have an economy which its eco- $^{-}$ nomic dynamic is in the maximum level.

\section{Analysis of cycle of money with and without escaping savings}

For the purposes of the mathematical approach of the cycle of money we use the prior equations subject to the next condition:

$\mu>\alpha_{p}>\alpha_{t}>\alpha_{s}$ 
For the purposes of the mathematical approach of the cycle of money we use the prior equations subject to the next conditions:

$\alpha \approx 0$

$x_{m} \approx m$

$c_{\alpha} \approx 0$

$c_{y}=c_{m}$

Then, using the prior statements we have that:

$\mu>\alpha_{p}>0$

Therefore, we use the equation from (1) to (14) and the next table for the coefficients of the values of the cycle of money. [2] Then, we have that:

\begin{tabular}{lll}
\hline Factors & Values & Values' \\
\hline $\mathrm{a}_{\mathrm{s}}$ & 0.6 & - \\
$\mathrm{a}_{\mathrm{t}}$ & 0.7 & - \\
$\mu$ & 0.9 & 0.9 \\
$\mathrm{a}_{\mathrm{p}}$ & 0.8 & 0.8 \\
\hline
\end{tabular}

Table: Compiling coefficients

The generator of this procedure used the coefficients which appeared on the previous table. Therefrom, the factors have an upper limit of 1 , and a lower limit 0 , but $s$ and $\tilde{s}$ are plausible to receive values greater than one as their mathematical structure allow this. After 461 iterations extracted the following diagram:

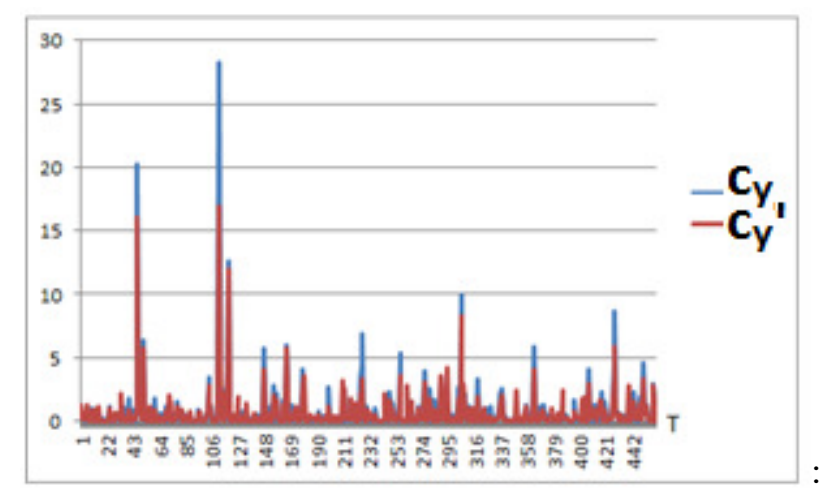

Figure 3: Comparison of cycle of money and of ideal cycle of money (see Appendix I and Appendix II)

In the previous scheme we obtain as we expected that the escaping savings diminish the financial liquidity.The $c_{y}$ expresses the lack of escaped savings (ideal case blue line)) is higher than $c_{y}^{\prime}$ the normal case (normal case - red line) We conclude that the nonreturn savings decline the economic dynamic of the market, and affect with their turn the tax and public policy. Therefore, the appropriate 
Challoumis $C$., The cycle of money with and without the escaped savings

tax and public policy determine the robustness of the economy.

\section{Conclusions}

This paper shows that an economy which protects the small and the medium economic units from the overlap of bigger economic units is much more productive than an economy which doesn't protect them with lower taxation. One economic tool of the authorities is the fixed length principle, meaning too have the higher taxesthe bigger companies (adding a constant-fix tax to the general one) which offer

\section{Appendix I}

This is the Matlab code for the case of Values (see Table):

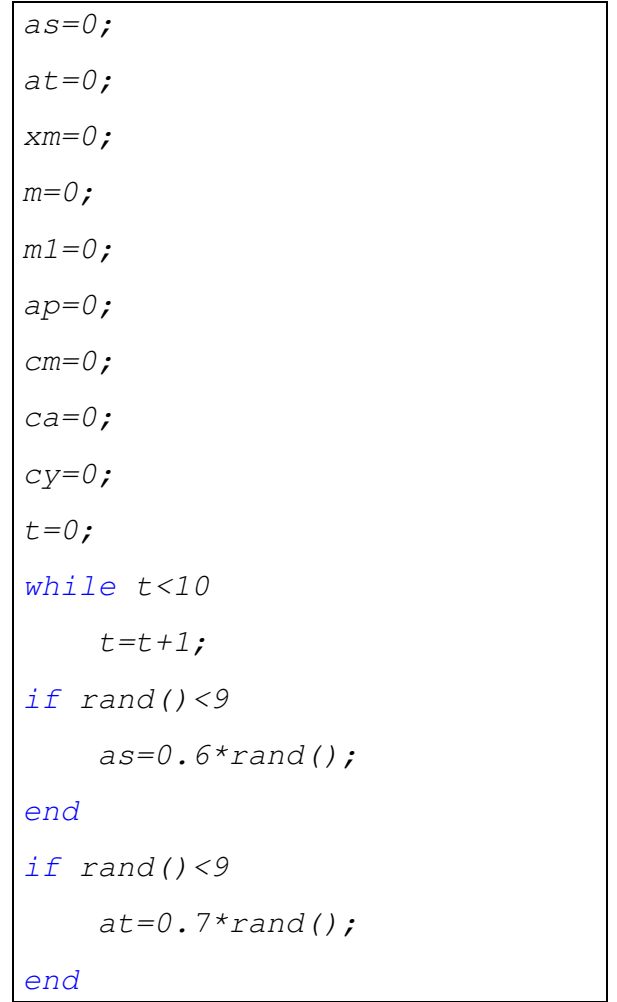

the same goods and services with the smaller one. Contemporary the bigger productive companies like the factories which don't overlap the smaller one (as the smaller one don't be able to offer this kind of production) should have low taxes to increase the exports and with that way to receive more money for the economy, growing the cycle of money. Therefore, the escaping saving is an important factor of the cycle of money, as defines growth or diminish of an economy accordingly.

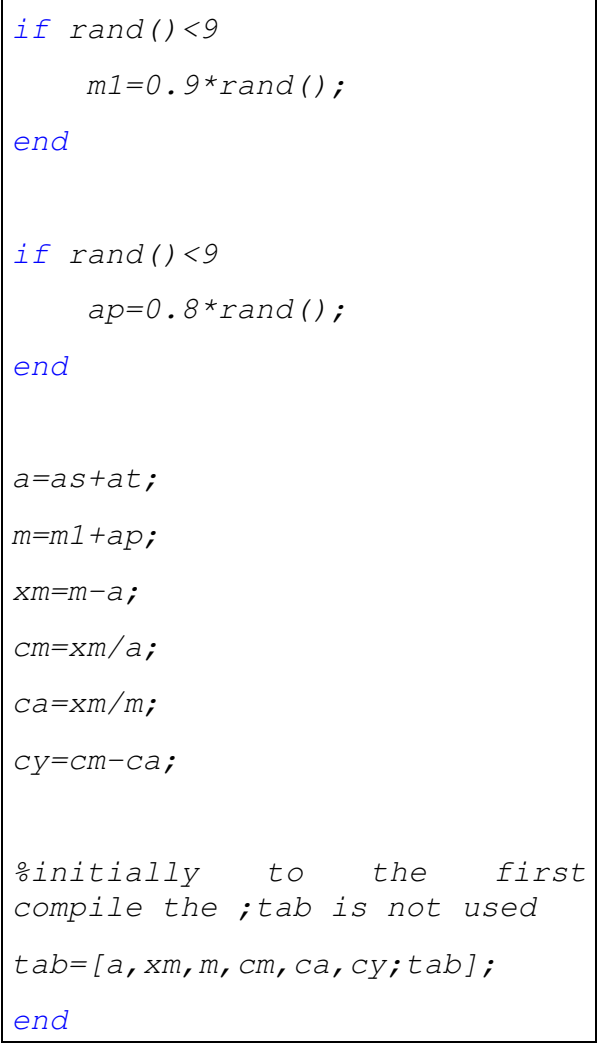

Ekonomski signali 96 


\section{Appendix II}

This is the Matlab code for the case of Values' (see Table):

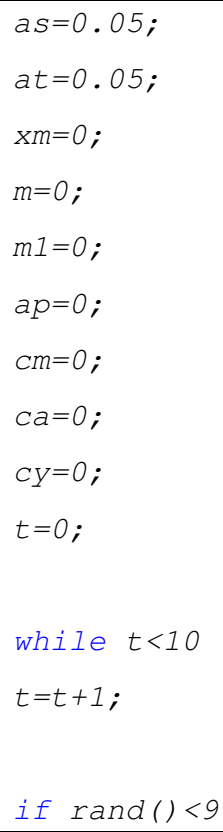

\section{References}

1. Argyris, C. \& Schon, D.A. (1974). Theory in Practice. San Francisco: Jossey-Bass.

2. Ariely, D., Loewenstein, G. \& Prelee D. (2003), Coherent arbitrariness: Stable demand curves without stable preferences. Quarterly Journal of Economics(118), 73-105.

3. Boland, Lawrence A. (1991), The Methodology of Economic Model Building. London and New York: Routledge.

4. Camerer, C. F. (2003), The behavioral challenge to econo- $m 1=0.9 *$ rand ();

end

if $\operatorname{rand}()<9$

$a p=0.8 *$ rand ()$;$

end

$a=a s+a t$

$m=m 1+a p ;$

$x m=m-a$;

$c m=x m / a$;

$c a=x m / m$;

$c y=c m-c a$;

oinitially to the first compile the ; tab is not used

$t a b=[a, x m, m, c m, c a, c y ; t a b]$;

end

mics: Understanding normal people. Federal Reserve of Boston meeting "How Humans Behave", Caltech, Pasadena CA 91125, 1-34.

5. Challoumis, C. (2019). The arm's length principle and the fixed length principle economic analysis, World Scientific News, 115-118,pp.1-12

6. Challoumis, C. (2017). Quantification of Everything (a Methodology for Quantification of Quality Data with Appli-cation and to Social and Theoretical Sciences) Available at SSRN: https://ssrn.com/abstract $=3136$ 014 
Challoumis $C$., The cycle of money with and without the escaped savings

7. Challoumis, C. (2018). Methods of Controlled Transactions and the Behavior of Companies According to the Public and Tax Policy, Economics, 6(1), 33-43. doi: https://doi.org/10.2478/eoik2018-0003

8. Challoumis, C. (2018), The impact factor of health on the economy using the cycle of money, Bulletin of the Transilvania University of Brasov, (2), 1-4.

9. Challoumis, C. (2018). Identification of significant economic risks to the international controlled transactions. Annals of Dunarea de Jos" University of Galati Fascicle I. Economics and Applied Informatics, (3), 15.

10. Challoumis, C. The Role of Risk to (2018), International Controlled Transactions. Annals of Dunarea de Jos" University of Galati Fascicle I. Economics and Applied Informatics, (3), 25.

11. Challoumis, C. (2019) "The R.B.Q. (Rational, Behavioral and Quantified) Model", Ekonomika, 98(1), pp. 6-18. doi: 10.15388/Ekon.2019.1.1.

12. Challoumis, C. (2019) "The R.B.Q. (Rational, Behavioral and Quantified) Model", Ekonomika, 98(1), pp. 6-18. doi: 10.15388/Ekon.2019.1.1.

13. Feinschreiber R. (2004), Transfer Pricing Methods An Application Guide (John Wiley \& Sons, New Jersey).
14. Gomes-Casseres, B., (1989), Ownership Structures of Foreign Subsidiaries: Theory and Evidence, Journal of Economic Behavior and Organization 11, 1-25.

15. Goodman N. (1978). Ways of Worldmaking. Indianapolis:Hackett.

16. Gordon L.V., (1976), Survey of Interpersonal Values - Revised Manual, Chicago: Science Research Associates

17. Habermas, J. (1968). Knowledge and Human Interests. Boston: Beacon Press.

18. Hallerberg, M., S. Bassinger (1998). "Internationalization and changes in tax policy in OECD countries: the importance of domestic veto players" Comparative Political Studies, 31 pp. 321-353

19. Hoynes, H.W., (1996). Welfare transfers in two-parent families: Labor supply and welfare participation under AFDC-UP. Econometrica, 64(2), 295-332.

20. King, M.A., D. Fullerton (1984). The Taxation of Income from Capital The University of Chicago Press, Chicago

21. Kuhn, T., (1962). The Structure of Scientific Revolutions. Chicago: University of Chicago Press.

22. Meier B.D. \& Rosenbaum D. T., (2000). Making single mothers work: Recent tax and welfare 
policy and its effects. National Tax Journal, 53(4), 1027-1061.

23. OECD (1991), Taxing Profits in a Global Economy OECD, Paris

24. OECD (1999), The OECD STAN Database for Industrial Analysis. OECD, Paris.

25. OECD (2000)., Towards Global Tax Cooperation. Report to the 2000 Ministerial Council Meeting and Recommendations by the Committee on Fiscal Affairs. OECD, Paris.

26. OECD (2017)., Transfer Pricing Guidelines for Multinational
Enterprises and Tax Administrations, OECD Publishing, Paris.

27. Rein, M. \& Schon, D. (1993). Reframing policy discourse in F. Fischer, John Forester. The argumentative turn in policy analysis and planning. UCL Press, 146-166.

28. Wilson J.D. (1986). A theory of interregional tax competition Journal of Urban Economics, 19(3), pp. 296-315

1 As tested parties considered the companies which participate in control transactions.

2 Sections II and III are almost the same with those of paper "Challoumis, Constantinos, The Theory of Cycle of Money (March 25, 2018). SSRN: https://ssrn.com/abstract=/", as they use the same base for their analysis.

3 See paper: Challoumis, Constantinos, Arm's Length Principle and Fix Length Principle Mathematical Approach (March 23, 2018). Available at SSRN: https://ssrn.com/abstract=

4 See paper: Challoumis, Constantinos, Analysis of Tangibles and Intangibles Transactions Subject to the Fixed Length Principle (March 17, 2018). Available at SSRN: https://ssrn.com/abstract=3142960

5 See paper: Challoumis, Constantinos, Analysis of Tangibles and Intangibles Transactions Subject to the Fixed Length Principle (March 17, 2018). Available at SSRN: https://ssrn.com/abstract=3142960 